\title{
Isocyanate toughened pCBT: Reactive blending and tensile properties
}

\author{
T. Abt ${ }^{1}$, A. Martínez de Ilarduya ${ }^{2}$, J. J. Bou ${ }^{2}$, M. Sánchez-Soto ${ }^{1 *}$ \\ ${ }^{1}$ Department of Materials Science, Centre Català del Plàstic, Universitat Politècnica de Catalunya, BarcelonaTech. \\ C/Colom 114, 08222 Terrassa, Spain \\ ${ }^{2}$ Department of Chemical Engineering, ETSEIB, Universitat Politècnica de Catalunya, BarcelonaTech, Diagonal 647, \\ 08028 Barcelona, Spain
}

Received 22 July 2012; accepted in revised form 29 September 2012

\begin{abstract}
Cyclic butylene terephthalate oligomers (CBT) were reacted in a ring-opening polymerization with three types of isocyanates: a bifunctional aromatic type, a bifunctional aliphatic type and a polymeric aromatic isocyanate. All reactions took place in a batch mixer. The use of 0.5 to $1 \mathrm{wt} \%$ isocyanate led to a dramatic increase in elongation at break of polymerized cyclic butylene terephthalate (pCBT), from 8 to above $100 \%$. The stiffness and strength of the modified pCBT, however, were found to slightly decrease. Proton nuclear magnetic resonance (NMR) analysis shows that the formation of thermally stable amide groups is the dominant chain extension reaction mechanism. Gel content measurements suggest a linear structure for samples containing bifunctional isocyanates while pCBT modified with polyfunctional isocyanate exhibited some gel formation at higher isocyanate content. Melting and crystallization temperatures as well as degree of crystallinity were found to decrease with increasing isocyanate content. No phase separation was detected by scanning electron microscopy (SEM) analysis. Moreover, a high degree of polymerization is deduced due to the absence of CBT oligomer crystals.
\end{abstract}

Keywords: mechanical properties, cyclic butylene terephthalate, $p C B T$, isocyanate, toughening

\section{Introduction}

The in situ ring-opening polymerization of cyclic butylene terephthalate oligomers is a promising route to replace thermosetting polymers in composites and has become of great interest. CBT oligomers melt at low temperatures $\left(120-160^{\circ} \mathrm{C}\right)$ and exhibit a water-like viscosity prior to polymerization. Due to this very low initial viscosity, fiber reinforcements can be readily impregnated. After impregnation, the molten CBT oligomers quickly polymerize in an entropically driven, athermal ring-opening polymerization (ROP) without releasing volatile organic compounds. This process yields pCBT, a thermoplastic polyester with high molecular weight [1-3]. So far, continuous fiber reinforced composites made from CBT and glass fibers [3-8], basalt fibers [9], and carbon fibers [10-13] have been reported. Moreover, a hydrogenated nitrile rubber (HNBR) was modified with CBT and the HNBR/CBT hybrids exhibited improved mechanical and triblogical properties compared to pristine HNBR [14]. CBT has also been extensively used in nanocomposites due to the low melt viscosity prior to ROP which is advantageous for a good dispersion of the reinforcement. Nanocomposites with nanosilica [15], multiwalled carbon nanotubes [16-19], graphene [20] and organically modified montmorillonite [21-24] have been prepared. Various researchers obtained an improved dispersion or intercalation/exfoliation in the case of organoclays compared to conventional melt blended PBT nanocomposites. The good dispersion and exfoliation of nanoparticles in pCBT resulted

\footnotetext{
${ }^{*}$ Corresponding author, e-mail: m.sanchez-soto@upc.edu (C) BME-PT
} 
in improved thermomechanical properties $[15,17$, $20,21]$ and better thermal stability $[18,20,24]$.

However, pCBT was found to be brittle $[4,5,7,9$, $13,25]$. This brittleness is caused by the formation of large perfect crystals with a lack of intercrystalline tie molecules $[3,13,26]$. Another reason for brittleness is a low molecular weight, which can be caused by hydrolysis if moisture is present during the ROP. Moreover, water can negatively affect the catalyst, which also leads to a lower molecular weight $[9,27]$. Several researchers have addressed this problem by copolymerizing CBT with poly (ethylene-co-vinyl acetate) [28], poly(vinyl butyral) [29], E-caprolactone [30] and polycaprolactone [4, 31]. This leads to a decreased crystallinity with less perfect crystals and an increased elongation at break together with a deep decrement of other relevant mechanical properties such as stiffness and strength.

Recently, we showed that reactive chain extension of pCBT with a bifunctional epoxy resin is a useful way to increase the molecular weight and to toughen pCBT without considerably affecting other properties [25]. The bifunctional epoxide groups react with the terminal carboxyl groups of two or more pCBT chains, increasing molecular weight and causing an improvement in toughness. However, the chain extension reaction of $\mathrm{pCBT}$ and epoxy resin is rather slow and requires high reaction temperatures. Additionally, it can result in considerable gel formation when there is an excess of epoxy resin. Therefore an addition-type chain extender with no by-products, higher reactivity and capable of yielding a linear macromolecular structure is desirable. Of the available groups of chain extenders for polyesters, isocyanates (NCO) are promising. They show higher reactivity than epoxides and readily react at moderate temperatures with active hydrogen containing compounds $[27,32,33]$. The reaction can be promoted by metals in the form of organometallics and/or salts of organic acids. Tin compounds such as dibutyl tin dilaurate and tin (II) octoate are particularly effective, so the reaction can even be conducted at room temperature $[34,35]$. This high reactivity and versatility make isocyanates an important group of chemicals and they are used as building blocks, e.g. as hard segments in polyurethane chemistry. Linear, branched and crosslinked structures can be obtained with isocyanates, depending on functionality and stoichiometry. Isocyanates can be used as compatibilizers for partially miscible polymer blends [36] as well as chain extenders or toughening agents to improve the properties; particularly the toughness of recycled poly(ethylene terephthalate) $[33,36]$, polylactide [37], and poly(butylene terephthalate) [38]. These properties render isocyanates a useful group of chain extender and toughening agents for pCBT. To the best of our knowledge, there has been no publication on this subject. In the present work we have studied the role of different isocyanates on the ring-opening polymerization and the properties of CBT. The resultant structure and properties have been analyzed and discussed.

\section{Experimental section \\ 2.1. Materials}

Cyclic butylene terephthalate oligomers were used in this study, namely one-component CBT $160^{\circledR}$, containing butylchlorotin dihydroxide as a catalyst and were provided in granule form from Cyclics Europe GmbH (Schwarzheide, Germany). The CBT was ground into a fine powder using a mortar and pestle.

Three different types of isocyanates were used; their chemical structures are depicted in Figure 1. Hexamethylene diisocyanate (referred to as HDI) is a liquid aliphatic diisocyanate and 4,4'-methylenebis(phenyl isocyanate) (referred to as MDI) is a solid aromatic diisocyanate. Both types were analytical grades from Sigma-Aldrich and used as received. A polymeric methylene diphenyl diiso-

a)

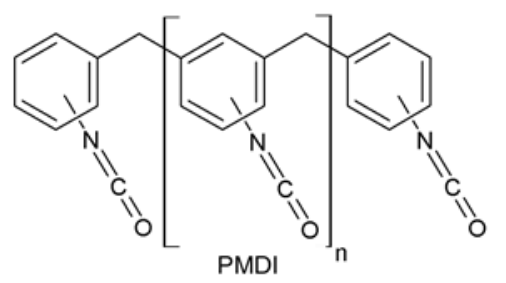

b)
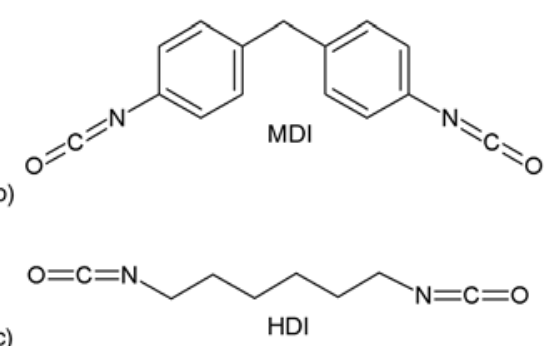

Figure 1. Chemical structures of polymeric isocyanate (a), aromatic 4,4'-methylenebis(phenyl isocyanate) (b) and aliphatic hexamethylene diisocyanate (c) 
cyanate (referred to as PMDI) was purchased from BASF Poliuretanos Iberia S.A., Rubí, Spain and used as received. The PMDI is a brown, viscous liquid of grade IsoPMDI 92410. According to the material data sheet the PMDI was based on 4,4'methylenebis(phenyl isocyanate) and contained oligomers with an average functionality of $\sim 2.7$ and a NCO content of $31.8 \%$.

\subsection{Sample preparation}

CBT and the corresponding amount of each isocyanate $(0.25,0.5,0.75$ and $1 \mathrm{wt} \%)$ were blended using mortar and pestle and vacuum dried at $80^{\circ} \mathrm{C}$ for $8 \mathrm{~h}$. The blends were stored in a desiccator over silica gel prior to in-situ polymerization and simultaneous reactive blending in a batch mixer. After polymerization the polymer was collected, ground into granules and vacuum dried at $80^{\circ} \mathrm{C}$ for $8 \mathrm{~h}$. An IQAP LAP PL-15 hot plate press was used to compression mould the dried granules at $250^{\circ} \mathrm{C}$ for $5 \mathrm{~min}$ between two PTFE films in ambient atmosphere. The samples were then rapidly cooled to room temperature in the cold stage of the press. The resulting pCBT/NCO films had dimensions of ca. $150 \times 150 \times$ $0.5 \mathrm{~mm}^{3}$ and were used to extract samples for further characterization. Neat CBT was equally processed for comparison.

\subsection{Characterization}

\subsubsection{Torque versus time measurements}

The CBT/NCO blends were in-situ polymerized in a Brabender Plasti-Corder W50EHT (Duisburg, Germany), equipped with a torque measuring system. Around $40 \mathrm{~g}$ of the $\mathrm{CBT} / \mathrm{NCO}$ blends were polymerized in the mixing chamber of the Brabender batch mixer at $230^{\circ} \mathrm{C}$ and $60 \mathrm{~min}^{-1}$ rotor speed under a blanket of nitrogen to minimize hydrolysis. The preheated mixing chamber was purged with nitrogen for $5 \mathrm{~min}$ and the predried CBT/NCO blend was introduced. Then the nitrogen blanket was introduced again and after a predetermined time the mixing was stopped. The material was collected from the mixing chamber and allowed to cool to room temperature.

\subsubsection{Gel content}

The insoluble content of the isocyanate-modified pCBT samples was determined by dissolving around $50 \mathrm{mg}$ of sample in $5 \mathrm{~mL}$ of a mixture of $\mathrm{CHCl}_{3} /$
TFA (9/1) at ambient temperature with agitation for $30 \mathrm{~min}$. The solution was subsequently centrifuged and the soluble part was removed. The insoluble fraction was washed with $5 \mathrm{~mL}$ of the same solvent mixture two additional times and finally with $\mathrm{CHCl}_{3}$. It was then dried in an oven at $80^{\circ} \mathrm{C}$ for $12 \mathrm{~h}$ and weighted. The gel content was calculated by insoluble fraction weight over sample weight expressed in percent.

\subsubsection{Nuclear magnetic resonance spectroscopy (NMR)}

Proton NMR spectroscopy was used to determine the chemical structures of the NCO-modified pCBT samples. Spectra were collected on a Bruker AMX300 spectrometer operated at $300.1 \mathrm{MHz}$ at $363.1 \mathrm{~K}$. Sample concentrations were $1 \%(\mathrm{w} / \mathrm{v})$ and a $1,1,2,2-$ tetrachloroethane- $d_{2}$ solvent was used. A total of 640 scans with $32 \mathrm{k}$ data points were recorded with a relaxation delay of $2 \mathrm{~s}$.

\subsubsection{Differential scanning calorimetry (DSC)}

The thermal properties of neat pCBT and NCOmodified $\mathrm{pCBT}$ samples were determined by differential scanning calorimetry using a Perkin Elmer Pyris 1 device under nitrogen atmosphere. Compression moulded samples were heated from 30 to $250^{\circ} \mathrm{C}$ at a heating rate of $10^{\circ} \mathrm{C} / \mathrm{min}$, followed by an isothermal step of 3 minutes and then cooled from 250 to $30^{\circ} \mathrm{C}$ at a rate of $10^{\circ} \mathrm{C} / \mathrm{min}$. The sum of both melting enthalpies $\Delta H_{\mathrm{m} 1+2}$ of the second heating run was used to calculate the degree of crystallinity $\chi_{\Delta \mathrm{H}}$ of the samples according to Equation (1):

$\chi_{\Delta \mathrm{H}}=\frac{\Delta H_{\mathrm{m}}}{\Delta H_{\mathrm{m}}^{0}} \cdot 100[\%]$

The melting enthalpy $\Delta H_{\mathrm{m}}^{0}$ of fully perfect crystalline PBT is found in to be $142 \mathrm{~J} / \mathrm{g}$ according to literature $[13,16]$.

\subsubsection{Tensile tests}

The tensile properties were determined according to ISO 527 at room temperature and at a crosshead speed of $10 \mathrm{~mm} / \mathrm{min}$ on a Galdabini Sun 2500 (Galdabini, Italy) tensile testing machine. The strain was measured using a video extensometer. Type 1BA specimens were die cut from the above described compression moulded pCBT/NCO films. Presented values were averaged from a minimum of five spec- 
imens. The toughness in terms of strain energy was determined by integrating the area under the stressstrain curve from the origin until rupture.

\subsubsection{Scanning electron microscope (SEM)}

The morphologies of unmodified and NCO-modified $\mathrm{pCBT}$ were analyzed by SEM. Tensile test specimens were submerged in liquid $\mathrm{N}_{2}$ and equilibrated for $15 \mathrm{~min}$. The specimens were quickly extracted and cryo-fractured by bending. The fracture surfaces were then sputter coated with a thin gold layer using a Bal-Tec SCD005 Sputter Coater. SEM analysis was performed on a Jeol JSM-5610 scanning electron microscope and an acceleration voltage of $10 \mathrm{kV}$ was used.

\section{Results and discussion}

Isocyanates are well known to readily react with compounds that bear active hydrogen. The classical reaction in polyurethane chemistry is the reaction of an isocyanate group with an alcohol group where a urethane group is formed. The reactivity depends mainly on the chemical structure of the employed isocyanate and it was found that aromatic isocyanates are more reactive than aliphatic ones [33, 39]. Urethane bonds are thermally unstable and can dissociate at high temperatures. The decomposition temperature depends on the structures of the isocyanate and alcohol used. Generally, the higher the reactivity of the isocyanate-alcohol system, the lower the thermal stability of the formed urethane. The thermal stabilities of urethanes as reaction products of different isocyanate-alcohol systems are as follows: alkyl isocyanate-alkyl alcohol $\left(250^{\circ} \mathrm{C}\right)$ $>$ aryl isocyanate-alkyl alcohol $\left(200^{\circ} \mathrm{C}\right)>$ alkyl isocyanate aryl alcohol $\left(180^{\circ} \mathrm{C}\right)>$ aryl isocyanate-aryl alcohol $\left(120^{\circ} \mathrm{C}\right)[40]$. According to this sequence, the thermal stabilities of pCBT-isocyanate systems are

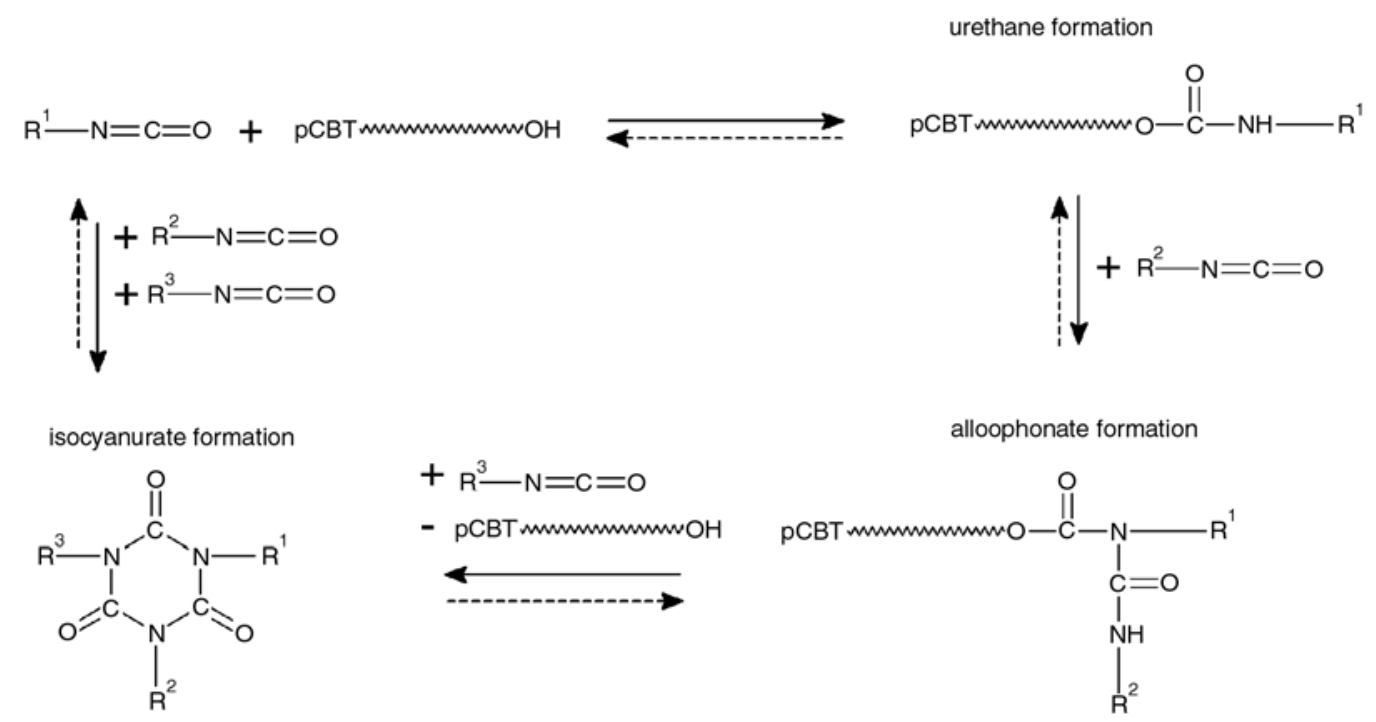

Figure 2. Possible reaction mechanisms of pCBT hydroxyl end groups and isocyanate functional groups

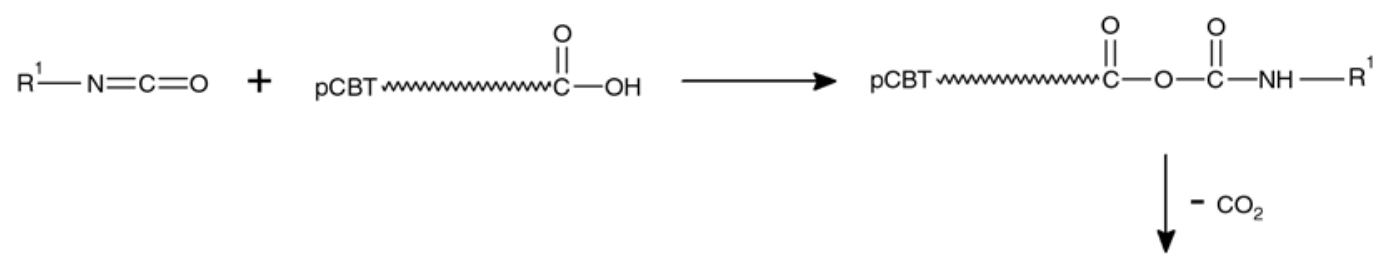

amide formation
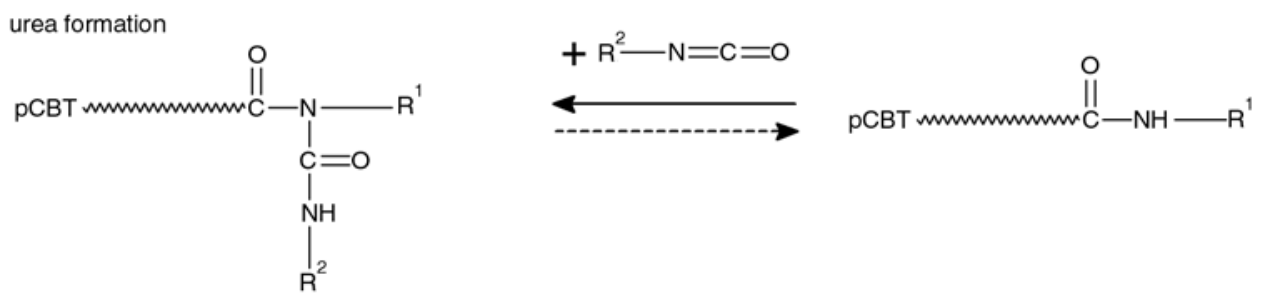

Figure 3. Possible reaction mechanisms of pCBT carboxyl end groups and isocyanate functional groups 
expected to be in the range of $200-250^{\circ} \mathrm{C}$. Due to their high reactivity, the isocyanate groups can also react with carboxyl end groups leading to amide groups and carbon dioxide as by-product. Amide bonds are thermally more stable than urethane or ester bonds due to their partial double bond character [41].

Secondary reactions with excess isocyanate and the previously formed urethane and amide groups can occur, resulting in allophanates (Figure 2) and ureas (Figure 3), respectively. Additionally, isocyanurates can arise from trimerization of isocyanate as well as from the reaction of allophanate and excess isocyanate. These secondary reactions lead to branching and finally to crosslinking of the polymer [27, $33,36,39,40,42]$. The kinetic rate constants of allophanate, urea and isocyanurate formation are much smaller than the ones of urethane and amide formation [39], and it is well known that these reactions are only favored at higher concentrations of isocyanate groups.

\subsection{Torque versus time measurements}

A chain extension reaction of (growing) pCBT chains and a bi- or polyfunctional chain extender causes an increase in molecular weight due to the coupling of multiple pCBT chains onto a chain extender molecule. This results in an increase in viscosity with reaction time. The ring-opening polymerization and the chain extension reaction were initially carried out in a Brabender batch mixer for a prolonged time $(60 \mathrm{~min})$ in order to visualize the torque/time signal, which is taken as an indicator for the viscosity evolution. The torque evolution is only shown for $15 \mathrm{~min}$. The optimum polymerization times were chosen from these graphs, as will be explained below. The torque curves are depicted in Figure 4; the maximum torque values and the corresponding times to reach the maximum torque are given in Table 1. The torque signal of neat CBT was first detected after 2 min which was considered to be the onset of the ROP. Before this time the melt viscosity of the molten CBT was below the detection limit of the measuring system. The torque curve reached a plateau after $9 \mathrm{~min}$ at ca. $6 \mathrm{Nm}$. Then it slowly increased and reached a maximum of $8 \mathrm{Nm}$ after $\sim 41 \mathrm{~min}$. After reaching the maximum, the torque decreased to $7 \mathrm{Nm}$ after $60 \mathrm{~min}$ probably due to thermo-mechanical degradation.
Regarding the CBT/NCO blends, apparently all three types of isocyanates act as promoters for the ring-opening polymerization when they are used in small concentrations (until $0.5 \mathrm{wt} \%$,) because the onset of the torque signal appears earlier (Figure 4). The aliphatic HDI was the most effective promoter when $0.5 \mathrm{wt} \%$ was used, showing an onset of only 30 s (c.f. Figure 4b). However, higher isocyanate contents $(>0.5 \mathrm{wt} \%)$ result in an increase of the onset time as well as of the time to reach the maximum torque value (Table 1).

A remarkable increase in torque can be seen for all blend compositions, confirming the chain extension reaction. The highest torque value was observed with aromatic MDI at a concentration of $0.75 \mathrm{wt} \%$, probably due to the higher reactivity of aromatic isocyanates compared to aliphatic ones.

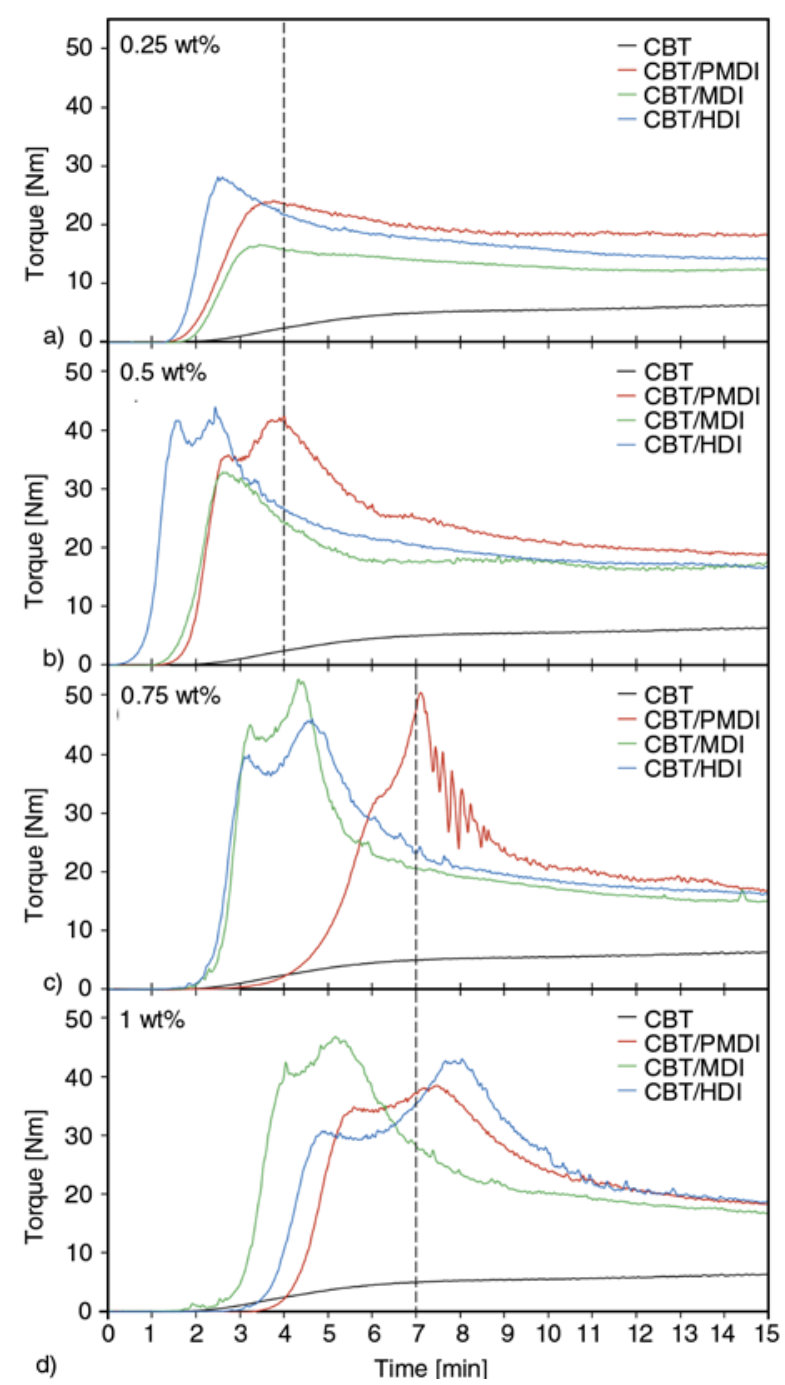

Figure 4. Torque vs. time plots of $\mathrm{CBT} / \mathrm{NCO}$ blends with an isocyanate content of (a) $0.25 \mathrm{wt} \%$, (b) $0.5 \mathrm{wt} \%$, (c) $0.75 \mathrm{wt} \%$ and (d) $1 \mathrm{wt} \%$ at $230^{\circ} \mathrm{C}$ and $60 \mathrm{rpm}$ under nitrogen atmosphere 
Table 1. Maximum torque values during ring-opening polymerization in the batch mixer, times to reach the maximum torque and gel contents prior to compression moulding. Tensile properties of compression moulded pCBT and pCBT/NCO samples.

\begin{tabular}{|c|c|c|c|c|c|c|c|c|}
\hline \multirow[b]{2}{*}{$\begin{array}{l}\text { Chain } \\
\text { extender }\end{array}$} & \multirow[b]{2}{*}{$\begin{array}{c}\text { Content } \\
\text { [wt\%] }\end{array}$} & \multicolumn{2}{|c|}{ Polymerization $^{a}$} & \multirow{2}{*}{$\begin{array}{c}\text { Gel content } \\
{[\%]}\end{array}$} & \multicolumn{4}{|c|}{ Tensile properties } \\
\hline & & $\begin{array}{l}\text { Torque max. } \\
\text { [Nm] }\end{array}$ & $\begin{array}{l}\text { Time }^{\mathrm{b}} \\
{[\mathrm{min}]}\end{array}$ & & $\begin{array}{c}\text { Tensile } \\
\text { modulus } \\
\text { [GPa] }\end{array}$ & $\begin{array}{c}\text { Tensile } \\
\text { strength } \\
\text { [MPa] }\end{array}$ & $\begin{array}{c}\text { Elongation at } \\
\text { break } \\
{[\%]}\end{array}$ & $\begin{array}{c}\text { Strain } \\
\text { energy } \\
{\left[\mathrm{MJ} / \mathrm{m}^{3}\right]}\end{array}$ \\
\hline- & 0 & 7.7 & 40.7 & - & $2.9 \pm 0.3$ & $60 \pm 2$ & $8 \pm 1$ & $4.2 \pm 0.5$ \\
\hline \multirow{4}{*}{ PMDI } & 0.25 & 24.0 & 3.7 & - & $2.8 \pm 0.3$ & $57 \pm 1$ & $30 \pm 4$ & $13.5 \pm 1.7$ \\
\hline & 0.5 & 42.4 & 4.0 & 2.2 & $2.6 \pm 0.3$ & $55 \pm 3$ & $184 \pm 94$ & $77.9 \pm 41.1$ \\
\hline & 0.75 & 50.4 & 7.1 & 1.2 & $2.6 \pm 0.2$ & $55 \pm 1$ & $167 \pm 84$ & $70.9 \pm 38.3$ \\
\hline & 1 & 38.5 & 7.5 & 31.5 & $2.6 \pm 0.2$ & $51 \pm 1$ & $215 \pm 28$ & $87.1 \pm 11.7$ \\
\hline \multirow{4}{*}{ MDI } & 0.25 & 16.6 & 3.4 & - & $2.6 \pm 0.4$ & $56 \pm 1$ & $25 \pm 18$ & $8.7 \pm 4.3$ \\
\hline & 0.5 & 32.9 & 2.6 & - & $2.7 \pm 0.4$ & $55 \pm 1$ & $141 \pm 71$ & $57.0 \pm 29.9$ \\
\hline & 0.75 & 52.7 & 4.3 & - & $2.6 \pm 0.1$ & $55 \pm 1$ & $174 \pm 68$ & $71.9 \pm 30.0$ \\
\hline & 1 & 46.8 & 5.2 & - & $2.7 \pm 0.2$ & $55 \pm 1$ & $79 \pm 11$ & $30.5 \pm 4.6$ \\
\hline \multirow{4}{*}{ HDI } & 0.25 & 28.1 & 2.5 & - & $2.4 \pm 0.2$ & $60 \pm 1$ & $24 \pm 9$ & $9.9 \pm 4.9$ \\
\hline & 0.5 & 43.9 & 2.4 & - & $2.8 \pm 0.3$ & $55 \pm 1$ & $143 \pm 85$ & $61.2 \pm 28.7$ \\
\hline & 0.75 & 46.1 & 4.6 & - & $2.7 \pm 0.7$ & $54 \pm 1$ & $227 \pm 35$ & $95.4 \pm 18.4$ \\
\hline & 1 & 43.0 & 8.0 & - & $2.8 \pm 0.2$ & $54 \pm 1$ & $109 \pm 21$ & $44.9 \pm 9.0$ \\
\hline
\end{tabular}

aPolymerization conditions: $230^{\circ} \mathrm{C}, 60 \mathrm{rpm}, \mathrm{N}_{2}$ atmosphere

${ }^{\mathrm{b}}$ Time to reach maximum torque

When only $0.25 \mathrm{wt} \%$ chain extender was used, a single torque maximum was observed. At higher isocyanate concentrations a second maximum appeared. This may be due to intermediate reactions, i.e. an initial urethane formation corresponding to the first maximum, subsequently followed by urethane dissociation into isocyanates and hydroxyl groups, leading to a torque decrease and finally amide formation, resulting in the second torque maximum. This urethane dissociation during processing will be discussed in detail in the NMR section.

After prolonged processing times $(>10 \mathrm{~min})$, all curves decreased to an average value of $\sim 17 \mathrm{Nm}$ after $15 \mathrm{~min}$. This suggests that an equilibrium was reached and all blends, regardless of their isocyanate content, exhibited a similar molecular weight. Raffa et al. [32] came to a similar conclusion working with recycled PET and its chain extension with diand multifunctional isocyanates. They found a plateau value of both molecular weight and melt viscosity above a threshold amount of isocyanate and ascribed this stationary condition to a mutual compensation of chain extension and degradation processes.

It is apparent from Figure 4 that higher isocyanate concentrations require a longer time to fully react. The peak of the torque curve was considered as the highest molecular weight of the formed pCBT/NCO. Therefore a polymerization time of 4 min was cho- sen for blends containing 0.25 and $0.5 \mathrm{wt} \%$ isocyanate, whereas neat $\mathrm{CBT}$ and blends with isocyanate concentrations of 0.75 and $1 \mathrm{wt} \%$ were polymerized for $7 \mathrm{~min}$. The two dashed vertical lines in Figure 4 represent these selected polymerization times 4 and $7 \mathrm{~min}$.

Fresh CBT/NCO blends were polymerized in the batch mixer under the same conditions for 4 and 7 min, respectively. A gel-like texture was noticed in pCBT/PMDI samples with higher isocyanate concentrations when the materials were collected from the mixing chamber, therefore the gel content was determined.

\subsection{Gel content}

The insoluble part of the NCO-modified pCBT samples was determined by dissolution, centrifugation, washing and filtration; the results are compiled in Table 1. Samples modified with bifunctional MDI or HDI were completely soluble, suggesting a linear chain structure. Only samples containing polyfunctional PMDI showed gel formation, namely 2.2 and $1.2 \%$ insoluble content for 0.5 and $0.75 \mathrm{wt} \%$ PMDI concentration. The highest insoluble content of $31.5 \%$ was observed for $1 \mathrm{wt} \%$ PMDI content. Note that gelling was only observed in samples after insitu polymerization in the batch mixer. All compression moulded samples were completely soluble for NMR analysis. This leads to the assumption that 
these crosslinked structures in pCBT/PMDI samples changed to linear or branched structures during compression moulding.

\subsection{NMR}

Proton NMR analysis was used to determine the chemical structures of $\mathrm{pCBT}$ and chain extended pCBT obtained from compression moulding. The structures and corresponding spectra are shown in Figure 5.

In the spectrum of neat $\mathrm{pCBT}$, the signal at $1.9 \mathrm{ppm}$ is assigned to shielded methylene protons, the triplet at $3.7 \mathrm{ppm}$ corresponds to methylenes attached to terminal hydroxyl groups $\left(-\mathrm{CH}_{2} \mathrm{OH}\right)$, the peak at $4.4 \mathrm{ppm}$ is assigned to oxymethylene protons and the one at $8.0 \mathrm{ppm}$ is assigned to the aromatic protons.

The spectra of the $\mathrm{pCBT} / \mathrm{NCO}$ samples revealed several additional peaks. Samples chain extended with aromatic isocyanate (i.e. MDI and PMDI) exhibited new peaks at 4.0, 7.2, 7.5 and $7.8 \mathrm{ppm}$. The peaks at $4.0 \mathrm{ppm}$ are due to methylene protons of the reacted MDI, the doublets at 7.2 and $7.5 \mathrm{ppm}$ are assigned to aromatic protons of the reacted MDI whereas the doublet at $7.9 \mathrm{ppm}$ is assigned to aromatic protons of the terephthalic moiety which are linked to one ester group and one amide group in para position.

In the case of samples containing aliphatic isocyanates (i.e. HDI), new peaks at 3.1, 3.4, 4.1, 6.2 and $7.8 \mathrm{ppm}$ arose. The weak peaks at 3.1 and $4.1 \mathrm{ppm}$ are assigned to urethane formation of pCBT hydroxyl end groups and HDI [42]. More pronounced peaks at 3.4, 6.2 and $7.8 \mathrm{ppm}$ are due to amide formation. Furthermore, no signal of remaining unreacted isocyanates could be detected, suggesting a complete reaction of the isocyanates. Moreover, no crosslinked structures such as allophanates, ureas or biurets have been detected in compression moulded samples by NMR which is also concordant with gel content measurements. It can be also seen that the number of terminal hydroxyl groups (c.f. triplet at $3.7 \mathrm{ppm}$ ) is similar for all samples. A possible explanation is that the isocyanate reacted with terminal hydroxyl groups in the first stage but due to the low thermal stability of urethane at the processing temperature the formed urethane groups dissociated back into $-\mathrm{NCO}$ and $-\mathrm{OH}$ groups. The liberated

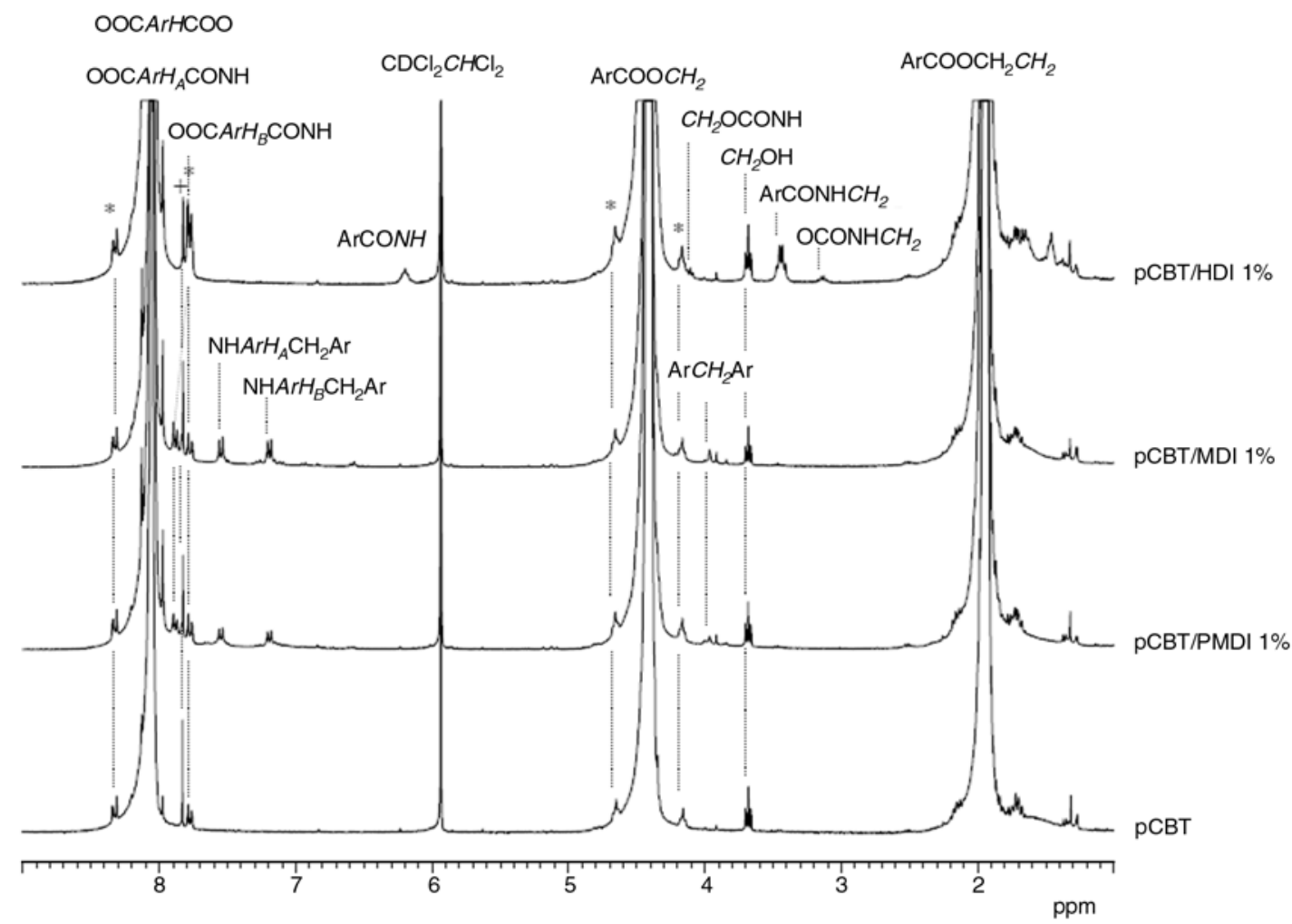

Figure 5. ${ }^{1} \mathrm{H}$ NMR spectra of pCBT and chain extended pCBT samples with peak assignments. $(*)$ Satellite signals; $(+)$ Unreacted pCBT; (Ar) Aromatic ring. 
isocyanate reacted then with the pCBT terminal $\mathrm{COOH}$ groups, forming thermally stable amide groups and liberating $\mathrm{CO}_{2}$.

Further proton NMR experiments were performed to clarify this assumption and to see the influence of the compression moulding step on the chain extension reaction. Two chain extended samples which contained $1 \mathrm{wt} \%$ HDI were analyzed, before and after compression moulding. The corresponding spectra with peak assignments are depicted in Figure 6.

It can be seen that the sample before compression moulding showed higher intensity for the peaks at
3.1 and $4.1 \mathrm{ppm}$ assigned to urethane, compared to the sample after compression moulding. Moreover, the triplet at $3.7 \mathrm{ppm}$ assigned to hydroxyl end groups and the peaks assigned to amide groups $(3.4,6.2$ and $7.8 \mathrm{ppm}$ ) increased after compression moulding. This supports the assumption that during compression moulding the urethane groups dissociated into isocyanate and hydroxyl end groups, the former subsequently reacting with pCBT carboxyl end groups. Apart from the above mentioned effect, the increase in hydroxyl end groups is believed to be also caused by hydrolysis to a certain degree during compression moulding in ambient atmosphere.
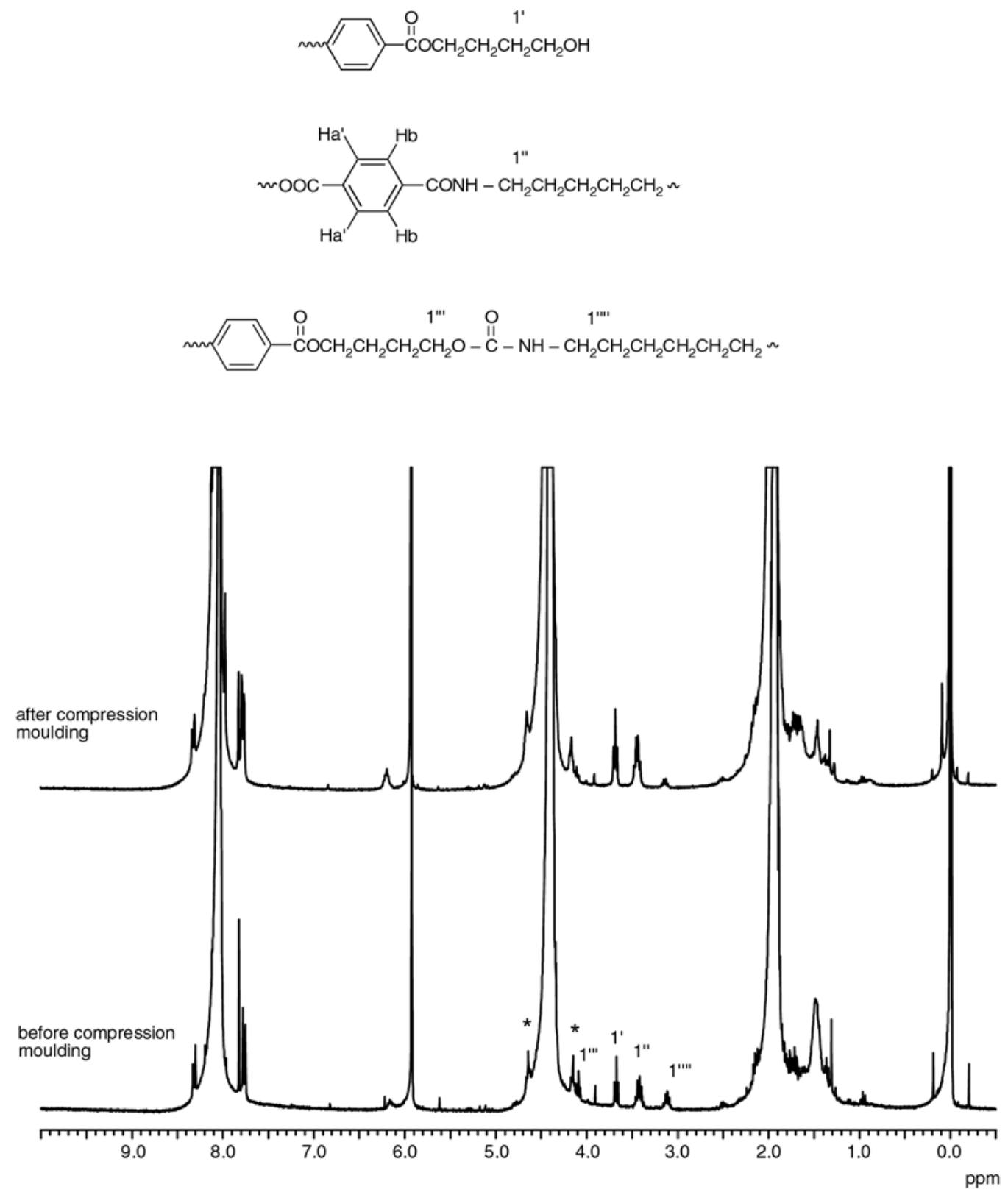

Figure 6. ${ }^{1} \mathrm{H}$ NMR spectra of pCBT/HDI $1 \%$ before and after compression moulding with peak assignments. $(*)$ Satellite signals. 
Therefore it can be concluded that the predominant reaction mechanism of $\mathrm{pCBT}$ and isocyanate is amide formation, although some urethane groups were detected in pCBT/HDI samples. The amount of formed urethane is less than $10 \%$ for $\mathrm{pCBT} / \mathrm{HDI}$ but this is difficult to quantify for samples containing aromatic isocyanate due to signal overlapping.

\subsection{Thermal properties}

The thermal properties of compression moulded $\mathrm{pCBT}$ and $\mathrm{pCBT} / \mathrm{NCO}$ samples were assessed by DSC analysis; the results are depicted in Figure 7 and Table 2. The observed trends are similar for all three types of used isocyanates, thus only the second heating scans of pCBT/PMDI are shown as representative sample series. Unmodified pCBT shows a minor melting peak at $215^{\circ} \mathrm{C}$ and a major peak at $224^{\circ} \mathrm{C}$, typical for polyesters and ascribed to the recrystallization and melting of imperfect crystal structures [22]. The degree of crystallinity was calculated from the sum of both melting enthalpies and was found to be $36 \%$. During the cooling scan the crystallization peak was observed at $193^{\circ} \mathrm{C}$.

Regarding isocyanate modified pCBT samples, a general depression of crystallization and melting temperatures and their corresponding enthalpies can be observed (Table 2). Both melting temperatures decreased up to $3^{\circ} \mathrm{C}$ and crystallization temperatures reduced up to $6^{\circ} \mathrm{C}$. The crystallinity was most effectively decreased (about 7\%) when 0.75 wt $\%$ PMDI was used. Torres et al. [33], Zhang and coworkers [43] and Raffa et al. [32] modified recycled PET with di- and polyfunctional isocyanates

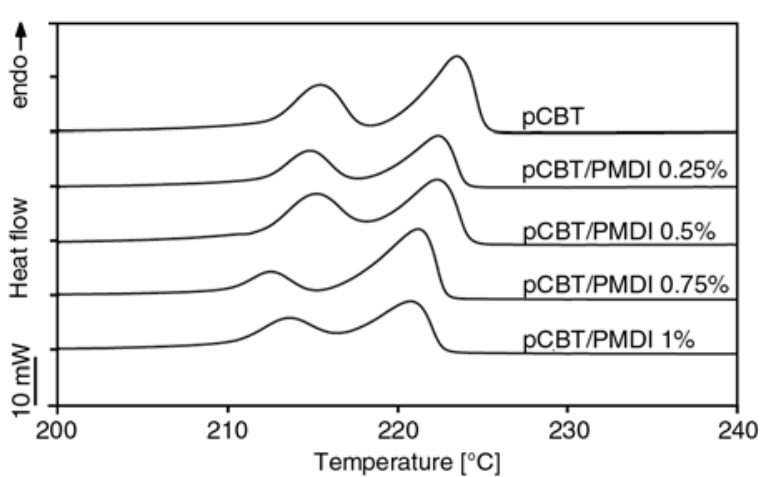

Figure 7. DSC second heating scan of compression moulded pCBT and pCBT/PMDI samples, heating and cooling rate of $10^{\circ} \mathrm{C} / \mathrm{min}$

and observed a similar tendency. This depression is due to the amide and urethane groups which form in the isocyanate reaction. These groups along the pCBT backbone disturb the chain symmetry and regularity and hence the crystallization rates are decreased, resulting in a decreased crystallinity and hence a higher toughness. Another consequence of the disturbed chain symmetry is a reduced lamellar thickness which leads to a decrease in melting temperature [33, 43]. No obvious tendency of the isocyanate modification on the glass transition of pCBT can be found, although most samples exhibited a slightly decreased $T_{\mathrm{g}}\left(1-2^{\circ} \mathrm{C}\right)$, indicating an increased chain mobility.

\subsection{Tensile properties}

The mechanical properties of compression moulded samples were assessed by tensile tests and the results are shown in Table 1 and Figure 8. Unmodified $\mathrm{pCBT}$ is brittle and fails at $\sim 8 \%$ elongation at

Table 2. Thermal properties of compression moulded pCBT and $\mathrm{pCBT} / \mathrm{NCO}$ samples

\begin{tabular}{|c|c|c|c|c|c|c|c|c|}
\hline \multirow{2}{*}{$\begin{array}{l}\text { Chain } \\
\text { extender }\end{array}$} & \multirow{2}{*}{$\begin{array}{c}\text { Content } \\
\text { [wt\%] }\end{array}$} & \multicolumn{2}{|c|}{ 1. Cooling } & \multicolumn{3}{|c|}{ 2. Heating } & \multirow{2}{*}{\begin{tabular}{|c|} 
Crystallinity \\
$\mathbf{X}_{\Delta \mathrm{H}}$ \\
{$[\%]$}
\end{tabular}} & \multirow{2}{*}{\begin{tabular}{|c|} 
Glass transition $^{*}$ \\
$\mathbf{T}_{\mathrm{g}}$ \\
$\left.\mathrm{\rho}^{\circ} \mathbf{C}\right]$
\end{tabular}} \\
\hline & & $\begin{array}{c}\mathbf{T}_{\mathbf{c}} \\
{\left[{ }^{\circ} \mathbf{C}\right]}\end{array}$ & $\begin{array}{l}\Delta \mathbf{H}_{\mathrm{m}} \\
{[\mathbf{J} / \mathbf{g}]}\end{array}$ & $\begin{array}{l}\mathbf{T}_{\mathrm{m} 1} \\
{\left[{ }^{\circ} \mathbf{C}\right]}\end{array}$ & $\begin{array}{l}\mathbf{T}_{\mathrm{m} 2} \\
{\left[{ }^{\circ} \mathbf{C}\right]}\end{array}$ & $\begin{array}{c}\Delta \mathbf{H}_{\mathrm{m} 1+2} \\
{[\mathrm{~J} / \mathrm{g}]}\end{array}$ & & \\
\hline- & 0 & 193.1 & -50.6 & 215.4 & 223.5 & 50.7 & 35.7 & 66.4 \\
\hline \multirow{4}{*}{ PMDI } & 0.25 & 191.0 & -49.3 & 214.8 & 222.4 & 47.9 & 33.7 & 66.5 \\
\hline & 0.5 & 190.7 & -47.8 & 215.1 & 222.3 & 46.9 & 33.0 & 67.0 \\
\hline & 0.75 & 189.7 & -47.3 & 212.5 & 221.3 & 40.8 & 28.7 & 63.9 \\
\hline & 1 & 187.0 & -44.4 & 213.5 & 220.8 & 42.5 & 29.9 & 65.3 \\
\hline \multirow{4}{*}{ MDI } & 0.25 & 192.1 & -46.7 & 215.5 & 223.6 & 44.1 & 31.1 & 64.0 \\
\hline & 0.5 & 189.8 & -44.9 & 213.5 & 221.0 & 43.9 & 30.9 & 65.2 \\
\hline & 0.75 & 190.4 & -49.3 & 213.4 & 221.7 & 43.1 & 30.3 & 64.7 \\
\hline & 1 & 188.9 & -48.8 & 213.2 & 221.2 & 45.0 & 31.7 & 63.4 \\
\hline \multirow{4}{*}{ HDI } & 0.25 & 189.7 & -44.9 & 214.0 & 221.8 & 45.2 & 31.8 & 65.6 \\
\hline & 0.5 & 188.7 & -42.8 & 213.0 & 221.1 & 41.3 & 29.1 & 65.6 \\
\hline & 0.75 & 189.6 & -48.2 & 214.4 & 222.5 & 46.3 & 32.6 & 63.0 \\
\hline & 1 & 189.4 & -47.7 & 214.0 & 222.0 & 46.2 & 32.5 & 62.7 \\
\hline
\end{tabular}

*As determined by DMTA in tensile mode in the temperature range $T=30-220^{\circ} \mathrm{C}, f=1 \mathrm{~Hz}, \varepsilon=0.05 \%$ 


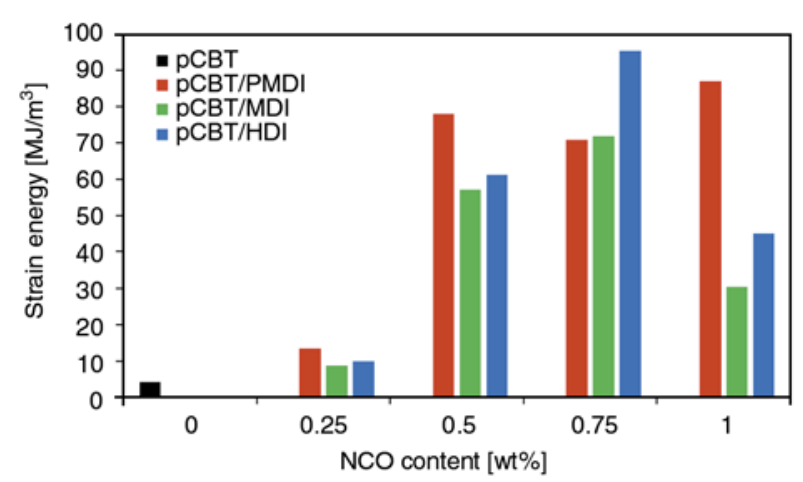

Figure 8. Strain energy versus NCO content for isocyanatemodified pCBT

break without yielding. By contrast, all isocyanatemodified samples showed a ductile behavior with an increased elongation at break. It can be seen that only $0.25 \mathrm{wt} \%$ isocyanate, regardless of type, results in a three-fold increase in failure strain although some samples failed in a brittle manner. All samples showed neck formation when the NCO content was increased to $0.5 \mathrm{wt} \%$. The maximum failure strain for MDI- (22-fold increase) and HDI- (28-fold increase) modified samples was observed at $0.75 \mathrm{wt} \%$ NCO content see Table 1). In the case of polymeric isocyanate a maximum failure strain (27fold increase) was found for $1 \mathrm{wt} \%$ PMDI. Toughness is better described by the strain energy calculated from tensile curves than by ultimate strain. Regarding the toughening effect by means of strain energy, the best result was obtained with $0.75 \mathrm{wt} \%$ HDI. But since PMDI was more effective over a wide NCO concentration range $(0.5-1 \mathrm{wt} \%$, see Figure 8), it appears to be the better toughening agent. Stiffness and strength decreased about $10 \%$ when samples contained the optimum amount of 0.5 to $1 \mathrm{wt} \%$ isocyanate. This decrease is small compared to other toughening methods like copolymerization and consistent with the marginal amount of isocyanate added. When these NCO-modified materials are employed, for instance in continuous fiber reinforced composites, the decrease in matrix stiffness will be compensated by the fibers. Additionally, the excellent toughness of isocyanate-modified pCBT may considerably increase the impact strength of composites.

\subsection{SEM}

In comparison to neat $\mathrm{pCBT}$, $\mathrm{pCBT} / \mathrm{NCO}$ samples were more difficult to break cryogenically. Therefore, small notches of ca. $2 \mathrm{~mm}$ depth were inserted with a razor blade on both sides of these specimens prior to cryo-fracture in order to ensure a brittle fracture. The micrographs of neat $\mathrm{pCBT}$ and $\mathrm{pCBT} /$ NCO $0.75 \mathrm{wt} \%$ are depicted in Figure 9. In all cases a single phase was observed and no signs of phase separation or incomplete reaction between pCBT and isocyanate could be found, indicating that the isocyanate had fully reacted with CBT which was also demonstrated by NMR. Moreover, no micronsized plate- or prism-like crystals of unpolymerized CBT were detected, indicating a high degree of conversion of CBT to pCBT $[14,25]$. Unmodified pCBT shows a smooth and uniform fracture surface. The small crests that are visible in Figure 9a are attributed to the rapid propagation of the crack during the fracture at low temperature that caused the crack front to oscillate. The detail at higher magnification $(\times 10000)$ clearly shows the absence of localized plastic deformation, indicating the brittle nature of unmodified pCBT (see detail of Figure 9a). Similarly, all modified samples fractured in a brittle manner (c.f. Figures 9b-9d), as expected due to the presence of notches and the low temperature used. Nevertheless, a somewhat rougher fracture surface compared to neat $\mathrm{pCBT}$ can be observed. This granular, rough structure is the result of the fracture of localized stretched matrix, as can be well observed at higher magnification [44]. This may indicate a certain amount of plastic deformation on a micrometer scale.

\section{Conclusions}

Cyclic butylene terephthalate oligomers were reacted in a ring-opening polymerization with three types of isocyanates: a bifunctional aromatic type, a bifunctional aliphatic type and a polymeric aromatic isocyanate. All reactions took place in a batch mixer. The isocyanate-modified samples showed a considerable torque increase compared to unmodified CBT, suggesting a higher molecular weight. Gel content measurements prior to compression moulding indicated a linear chain structure for the two bifunctional isocyanate-modified samples, whereas the polyfunctional PMDI-modified pCBT exhibited considerable gel formation at higher NCO contents. All compression moulded samples were completely soluble, indicating that the crosslinked structures in pCBT/PMDI samples changed to linear or branched structures during this second melting. Proton NMR analysis showed that the dominant chain extension 


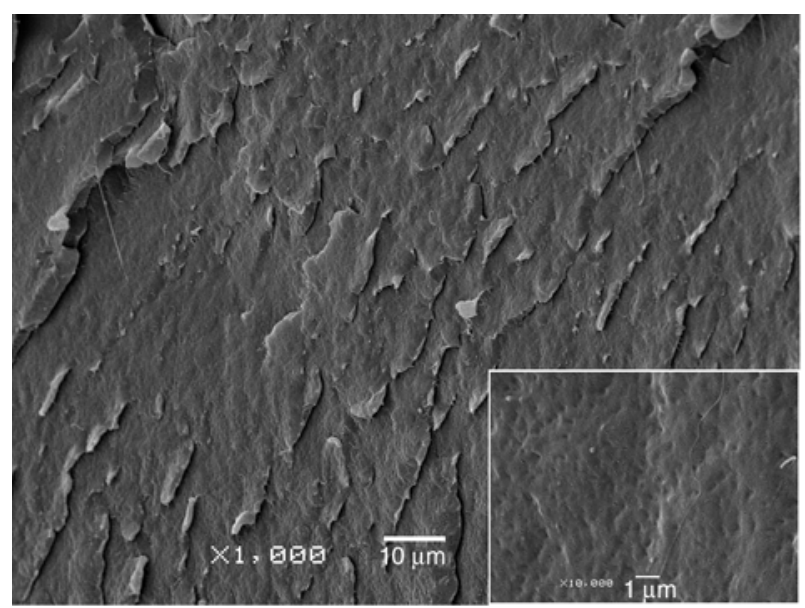

a)

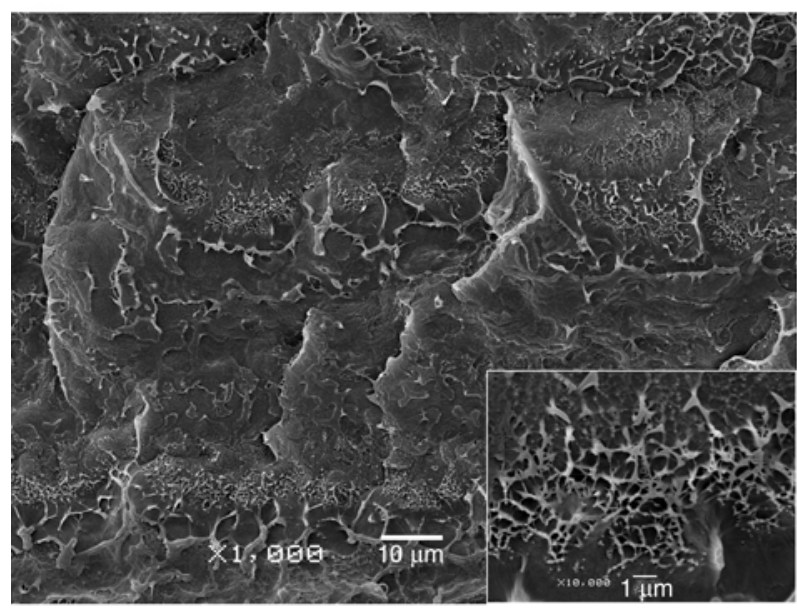

c)

Figure 9. SEM micrographs of compression moulded pCBT $\mathrm{pCBT} / \mathrm{HDI} 0.75 \%$ (d)

reaction mechanism is the formation of thermally stable amide groups. NMR further indicated that pCBT/NCO samples before compression moulding contained more urethane groups, compared to samples after compression moulding. Moreover, the number of hydroxyl end groups and amide groups slightly increased after the compression moulding step. This supports the assumption that the urethane groups dissociated at the processing temperature into isocyanate and hydroxyl end groups, the former subsequently reacted with pCBT carboxyl end groups. DSC analysis revealed a general depression of melting and crystallization temperatures as well as degree of crystallinity. This decrease in crystallinity accounts for the toughening effect of isocyanates. A 22-fold to 28-fold increase in elongation at break was observed in tensile tests when the pCBT contained 0.75 to $1 \mathrm{wt} \%$ isocyanate. The highest toughness by means of strain energy was obtained with $0.75 \mathrm{wt} \%$ HDI. The most effective toughening agent was PMDI because it showed good toughness

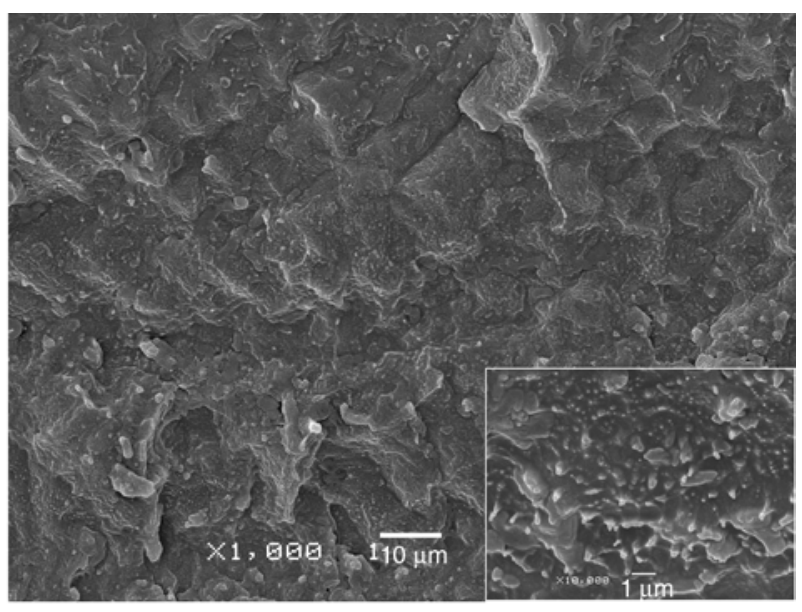

b)

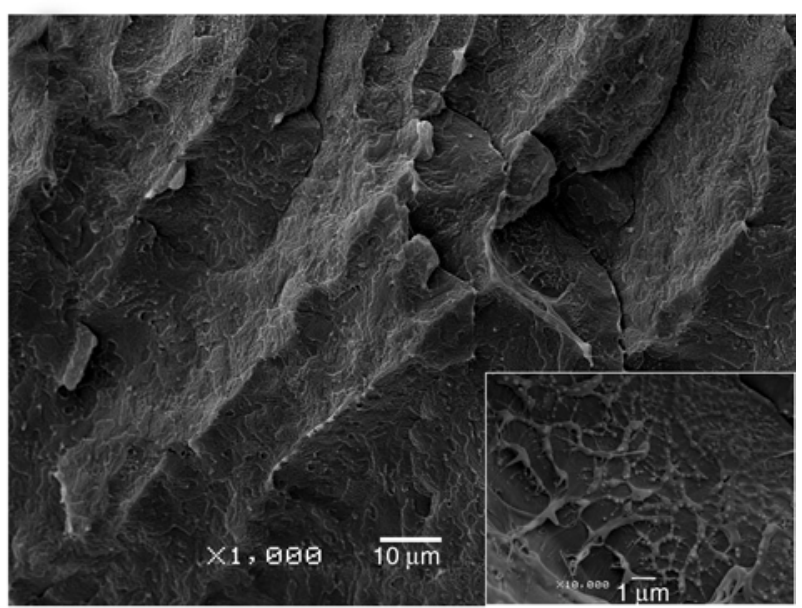

(a), pCBT/PMDI $0.75 \%$ (b), pCBT/MDI $0.75 \%$ (c) and

from 0.5 to $1 \mathrm{wt} \%$ NCO content. Stiffness and strength generally decreased about $10 \%$. The fracture surfaces of isocyanate-modified samples exhibited a network-like fibrillation in a SEM analysis, indicating plastic deformation on a micrometer scale. It can be concluded that a toughened pCBT can be obtained when 0.5 to $1 \mathrm{wt} \%$ isocyanate is added to the ring-opening polymerization of CBT.

\section{Acknowledgements}

Authors gratefully acknowledge the financial support received from the Spanish Government through the project PSS370000-2008-13.

\section{References}

[1] Brunelle D. J., Bradt J. E., Serth-Guzzo J., Takekoshi T., Evans T. L., Pearce E. J., Wilson P. R.: Semicrystalline polymers via ring-opening polymerization: Preparation and polymerization of alkylene phthalate cyclic oligomers. Macromolecules, 31, 4782-4790 (1998). DOI: $10.1021 / \mathrm{ma971491j}$ 
[2] Dion R. P., Bank D. H., Beebe M. C., Walia P., LeBaron P. C., Oelberg J. D., Barger M. A., Paquette M. S., Read M. D.: Polymerized macrocyclic oligomer nanocomposite compositions. U.S. Patent 2005/0059768 A1, USA (2005).

[3] Parton H., Baets J., Lipnik P., Goderis B., Devaux J., Verpoest I.: Properties of poly(butylene terephthatlate) polymerized from cyclic oligomers and its composites. Polymer, 46, 9871-9880 (2005).

DOI: $10.1016 /$ j.polymer.2005.07.082

[4] Baets J., Dutoit M., Devaux J., Verpoest I.: Toughening of glass fiber reinforced composites with a cyclic butylene terephthalate matrix by addition of polycaprolactone. Composites Part A: Applied Science and Manufacturing, 39, 13-18 (2008).

DOI: 10.1016/j.compositesa.2007.09.013

[5] Baets J., Godara A., Devaux J., Verpoest I.: Toughening of isothermally polymerized cyclic butylene terephthalate for use in composites. Polymer Degradation and Stability, 95, 346-352 (2010).

DOI: $10.1016 /$ j.polymdegradstab.2009.11.005

[6] Mäder E., Gao S-L., Plonka R., Wang J.: Investigation on adhesion, interphases, and failure behaviour of cyclic butylene terephthalate $\left(\mathrm{CBT}^{\circledR}\right) /$ glass fiber composites. Composites Science and Technology, 67, 31403150 (2007).

DOI: 10.1016/j.compscitech.2007.04.014

[7] Mohd Ishak Z. A., Leong Y. W., Steeg M., KargerKocsis J.: Mechanical properties of woven glass fabric reinforced in situ polymerized poly(butylene terephthalate) composites. Composites Science and Technology, 67, 390-398 (2007).

DOI: $10.1016 /$ j.compscitech.2006.09.012

[8] Parton H., Verpoest I.: In situ polymerization of thermoplastic composites based on cyclic oligomers. Polymer Composites, 26, 60-65 (2005).

DOI: $10.1002 /$ pc.20074

[9] Baets J., Devaux J., Verpoest I.: Toughening of basalt fiber-reinforced composites with a cyclic butylene terephthalate matrix by a nonisothermal production method. Advances in Polymer Technology, 29, 70-79 (2010).

DOI: $10.1002 / \mathrm{adv} .20176$

[10] Aurrekoetxea J., Zurbitu J., de Mendibil I. O., Agirregomezkorta A., Sánchez-Soto M., Sarrionandia M.: Effect of superelastic shape memory alloy wires on the impact behavior of carbon fiber reinforced in situ polymerized poly(butylene terephthalate) composites. Materials Letters, 65, 863-865 (2011).

DOI: $10.1016 /$ j.matlet.2010.12.020

[11] Balogh G., Czigány T.: Effect of air humidity on the mechanical properties of in situ polymerized cyclic butylene terephtalate matrix composites. Materials Science Forum, 659, 1-5 (2010).

DOI: 10.4028/www.scientific.net/MSF.659.1
[12] Balogh G., Czigány T.: Effect of low UD carbon fibre content on mechanical properties of in situ polymerised cyclic butylene terephtalate. Plastics, Rubber and Composites, 40, 121-124 (2011). DOI: $10.1179 / 1743289811 X 12988633927871$

[13] Yu T., Wu C. M., Chang C. Y., Wang C. Y., Rwei S. P.: Effects of crystalline morphologies on the mechanical properties of carbon fiber reinforcing polymerized cyclic butylene terephthalate composites. Express Polymer Letters, 6, 318-328 (2012).

DOI: $10.3144 /$ expresspolymlett.2012.35

[14] Karger-Kocsis J., Felhős D., Bárány T., Czigány T.: Hybrids of HNBR and in situ polymerizable cyclic butylene terephthalate (CBT) oligomers: Properties and dry sliding behavior. Express Polymer Letters, 2, 520-527 (2008).

DOI: $10.3144 /$ expresspolymlett.2008.62

[15] Jiang Z., Siengchin S., Zhou L-M., Steeg M., KargerKocsis J., Man H. C.: Poly (butylene terephthalate)/silica nanocomposites prepared from cyclic butylene terephthalate. Composites Part A: Applied Science and Manufacturing, 40, 273-278 (2009).

DOI: $10.1016 /$ j.compositesa.2008.12.003

[16] Baets J., Godara A., Devaux J., Verpoest I.: Toughening of polymerized cyclic butylene terephthalate with carbon nanotubes for use in composites. Composites Part A: Applied Science and Manufacturing, 39, 17561761 (2008).

DOI: 10.1016/j.compositesa.2008.08.004

[17] Romhány G., Vígh J., Thomann R., Karger-Kocsis J., Sajó I. E.: pCBT/MWCNT nanocomposites prepared by in situ polymerization of CBT after solid-phase high-energy ball milling of CBT with MWCNT. Macromolecular Materials and Engineering, 296, 544-550 (2011).

DOI: $10.1002 /$ mame.201000381

[18] Wu F., Yang G.: Synthesis and properties of poly(butylene terephthalate)/multiwalled carbon nanotube nanocomposites prepared by in situ polymerization and in situ compatibilization. Journal of Applied Polymer Science, 118, 2929-2938 (2010).

DOI: 10.1002/app.32625

[19] Wu F., Yang G.: Poly(butylene terephthalate)-functionalized MWNTs by in situ ring-opening polymerization of cyclic butylene terephthalate oligomers. Polymers for Advanced Technologies, 22, 1466-1470 (2011).

DOI: $10.1002 /$ pat.1762

[20] Fabbri P., Bassoli E., Bon S. B., Valentini L.: Preparation and characterization of poly (butylene terephthalate)/graphene composites by in-situ polymerization of cyclic butylene terephthalate. Polymer, 53, 897-902 (2012).

DOI: $10.1016 /$ j.polymer.2012.01.015 
[21] Berti C., Binassi E., Colonna M., Fiorini M., Zuccheri T., Karanam S., Brunelle D. J.: Improved dispersion of clay platelets in poly(butylene terephthalate) nanocomposite by ring-opening polymerization of cyclic oligomers: Effect of the processing conditions and comparison with nanocomposites obtained by melt intercalation. Journal of Applied Polymer Science, 114, 3211-3217 (2009).

DOI: 10.1002/app.30957

[22] Karger-Kocsis J., Shang P. P., Mohd Ishak Z. A., Rösch M.: Melting and crystallization of in-situ polymerized cyclic butylene terephthalates with and without organoclay: A modulated DSC study. Express Polymer Letters, 1, 60-68 (2007).

DOI: $10.3144 /$ expresspolymlett.2007.12

[23] Lanciano G., Greco A., Maffezzoli A., Mascia L.: Effects of thermal history in the ring opening polymerization of $\mathrm{CBT}$ and its mixtures with montmorillonite on the crystallization of the resulting poly(butylene terephthalate). Thermochimica Acta, 493, 61-67 (2009). DOI: $10.1016 /$ j.tca.2009.04.004

[24] Tripathy A. R., Burgaz E., Kukureka S. N., MacKnight W. J.: Poly(butylene terephthalate) nanocomposites prepared by in-situ polymerization. Macromolecules, 36, 8593-8595 (2003).

DOI: $10.1021 / \mathrm{ma} 021364+$

[25] Abt T., Sánchez-Soto M., Martínez de Ilarduya A.: Toughening of in situ polymerized cyclic butylene terephthalate by chain extension with a bifunctional epoxy resin. European Polymer Journal, 48, 163-171 (2012).

DOI: $10.1016 /$ j.eurpolymj.2011.10.017

[26] van Rijswijk K., Bersee H. E. N.: Reactive processing of textile fiber-reinforced thermoplastic composites An overview. Composites Part A: Applied Science and Manufacturing, 38, 666-681 (2007).

DOI: $10.1016 /$ j.compositesa.2006.05.007

[27] Guo B., Chan C-M.: Chain extension of poly(butylene terephthalate) by reactive extrusion. Journal of Applied Polymer Science, 71, 1827-1834 (1999).

DOI: $10.1002 /($ sici $) 1097-4628(19990314) 71: 11<1827$ :aid-app 13>3.0.co;2-7

[28] Bahloul W., Bounor-Legaré V., Fenouillot F., Cassagnau P.: EVA/PBT nanostructured blends synthesized by in situ polymerization of cyclic cBT (cyclic butylene terephthalate) in molten EVA. Polymer, 50, 25272534 (2009).

DOI: $10.1016 /$ j.polymer.2009.03.055

[29] Tripathy A. R., Chen W., Kukureka S. N., MacKnight W. J.: Novel poly(butylene terephthalate)/poly(vinyl butyral) blends prepared by in situ polymerization of cyclic poly(butylene terephthalate) oligomers. Polymer, 44, 1835-1842 (2003).

DOI: $10.1016 / \mathrm{s} 0032-3861(03) 00029-6$
[30] Tripathy A. R., MacKnight W. J., Kukureka S. N.: Insitu copolymerization of cyclic poly(butylene terephthalate) oligomers and $\varepsilon$-caprolactone. Macromolecules, 37, 6793-6800 (2004).

DOI: $10.1021 / \mathrm{ma} 0400517$

[31] Wu C-M., Huang C-W.: Melting and crystallization behavior of copolymer from cyclic butylene terephthalate and polycaprolactone. Polymer Engineering and Science, 51, 1004-1013 (2011).

DOI: $10.1002 /$ pen. 21910

[32] Raffa P., Coltelli M-B., Savi S., Bianchi S., Castelvetro V.: Chain extension and branching of poly(ethylene terephthalate) (PET) with di- and multifunctional epoxy or isocyanate additives: An experimental and modelling study. Reactive and Functional Polymers, 72, 50-60 (2012).

DOI: $10.1016 /$ j.reactfunctpolym.2011.10.007

[33] Torres N., Robin J. J., Boutevin B.: Chemical modification of virgin and recycled poly(ethylene terephthalate) by adding of chain extenders during processing. Journal of Applied Polymer Science, 79, 1816-1824 (2001).

DOI: $10.1002 / 1097-4628(20010307) 79: 10<1816:$ :aidapp $100>3.0 . c 0 ; 2-r$

[34] Houghton R. P., Mulvaney A. W.: Mechanism of tin (IV)-catalysed urethane formation. Journal of Organometallic Chemistry, 518, 21-27 (1996). DOI: $10.1016 / 0022-328 X(96) 06223-7$

[35] Segura D. M., Nurse A. D., McCourt A., Phelps R., Segura A.: Chemistry of polyurethane adhesives and sealants. in 'Handbook of adhesives and sealants' (ed.: Philippe C.) Elsevier, Amsterdam, Vol 1, 101-162 (2005). DOI: $10.1016 / \mathrm{S} 1874-5695(02) 80004-5$

[36] Tang X., Guo W., Yin G., Li B., Wu C.: Reactive extrusion of recycled poly(ethylene terephthalate) with polycarbonate by addition of chain extender. Journal of Applied Polymer Science, 104, 2602-2607 (2007). DOI: 10.1002/app.24410

[37] Chen B-K., Shen C-H., Chen S-C., Chen A. F.: Ductile PLA modified with methacryloyloxyalkyl isocyanate improves mechanical properties. Polymer, 51, 46674672 (2010).

DOI: 10.1016/j.polymer.2010.08.028

[38] Yin L., Shi D., Liu Y., Yin J.: Toughening effects of poly(butylene terephthalate) with blocked isocyanatefunctionalized poly(ethylene octene). Polymer International, 58, 919-926 (2009).

DOI: $10.1002 /$ pi.2613

[39] Lapprand A., Boisson F., Delolme F., Méchin F., Pascault J-P.: Reactivity of isocyanates with urethanes: Conditions for allophanate formation. Polymer Degradation and Stability, 90, 363-373 (2005). DOI: 10.1016/j.polymdegradstab.2005.01.045 
[40] Chattopadhyay D. K., Webster D. C.: Thermal stability and flame retardancy of polyurethanes. Progress in Polymer Science, 34, 1068-1133 (2009).

DOI: 10.1016/j.progpolymsci.2009.06.002

[41] van Bennekom A. C. M., Willemsen P. A. A. T., Gaymans R. J.: Amide-modified poly(butylene terepthalate): Thermal stability. Polymer, 37, 5447-5459 (1996).

DOI: $10.1016 / \mathrm{S} 0032-3861(96) 00355-2$

[42] Tuominen J., Kylmä J., Seppälä J.: Chain extending of lactic acid oligomers. 2. Increase of molecular weight with 1,6-hexamethylene diisocyanate and 2,2'-bis(2oxazoline). Polymer, 43, 3-10 (2002).

DOI: 10.1016/S0032-3861(01)00606-1
[43] Zhang Y., Guo W., Zhang H., Wu C.: Influence of chain extension on the compatibilization and properties of recycled poly(ethylene terephthalate)/linear low density polyethylene blends. Polymer Degradation and Stability, 94, 1135-1141 (2009).

DOI: $10.1016 /$ j.polymdegradstab.2009.03.010

[44] Roulin-Moloney A. C.: Fractography and failure mechanisms of polymers and composites. Springer, London (1989). 